\title{
UV Excimer Laser Photoproducts from Absorbing and Transparent Surfaces Covered by
} Aluminum Alkyl Adsorbates

\author{
Y. Zhang and M. Stuke* \\ Max-Planck-Institut für biophysikalische Chemie, Postfach 2841, D-3400 Göttingen, Federal Republic of \\ Germany (Received: February 10, 1988; In Final Form: January 20, 1989)
}

\begin{abstract}
Neutral atomic and molecular species, generated upon the interaction of UV excimer laser light with Al-alkyl/substrate interfaces, are detected by single-shot dye laser mass spectroscopy. The molecules studied at 308, 248, and $193 \mathrm{~nm}$ are trimethylaluminum (TMA), triethylaluminum (TEA), and triisobutylaluminum (TIBA). The substrate is either n-type Si(100) or $\mathrm{SiO}_{2}$ (quartz). The major aluminum-containing species detected are $\mathrm{Al}$ atoms and $\mathrm{AlH}$ and $\mathrm{AlCH}_{3}$ molecules. Their relative abundance is shown to depend on the adsorbate molecule and the wavelength chosen. Marked differences are observed between the case of the Al-alkyls photolyzed under collision-free conditions in the gas phase and when these molecules are adsorbed to a substrate.
\end{abstract}

\section{Introduction}

Laser-induced deposition of metal microstructures using organometallic compounds and pulsed UV excimer lasers can open up new possibilities for application specific integrated circuit (ASIC) fabrication, a technique by which only parts of an existing surface structure has to be modified. Deposition of aluminum for the customization of gate arrays is one possible example, and some experiments have already been performed using Al-alkyls ${ }^{1,2}$ and continuous wave UV and pulsed excimer lasers operating at 248 and $193 \mathrm{~nm}$. Important features to be fulfilled for the deposition process are that the deposition rate is reasonable, that the spatial control defined by the laser irradiation is maintained in the deposited structure, and certainly that the deposit is pure, especially free of carbon which increases the resistivity of the deposit uncontrollably. A better understanding of the basic processes involved may be obtained by studying independently the elementary photoprocesses of organometallic molecules in the gas phase under collision-free conditions ${ }^{3-5}$ and adsorbed onto various substrate materials.

In the following we shall describe experiments on Al-alkyls adsorbed onto light-absorbing and transparent surfaces of practical interest. Neutral atomic and molecular products generated, when UV excimer laser light is irradiating the adsorbate/surface interface, ${ }^{6}$ are detected. The technique used for detection is laser time-of-flight (TOF) mass spectroscopy. Therefore all products can be identified by mass and spectral features.? In addition, their velocity away from the surface can be measured with the required accuracy.

\section{Experimental Section}

The main components of the experimental setup have been described in detail in previous publications; ${ }^{7}$ therefore only a brief summary stressing the changes and additions will be given here. The substrate samples are located inside the ionization region of a differentially pumped laser ionization time-of-flight mass spectrometer analogous to the PMMA sample shown in Figure la of our recent publication on the excimer laser ablation from PMMA ${ }^{8}$ where the substrate was inserted about $10 \mathrm{~mm}$ below

(1) Cacouris, T.; Scelsi, G.; Shaw, P.; Scarmozzino, R.; Osgood, R. M.; Krehnavek, R. R. Appl. Phys, Lett. 1988, 52, 1865. Tsao, J. Y.; Ehrlich, D. J. App. Phys. Lett. 1984, 45, 617.

(2) Higashi, G. S.; Fleming, C. G. Appl. Phys. Lett. 1986, 48, 1051

(3) Zhang, Y.; Stuke, M. Chem. Phys. Lett. 1988, 149, 310.

(4) Zhang, Y.; Stuke, M. Jpn. J. Appl. Phys. 1988, 27, L1349.

(5) Stuke, M.; Zhang, Y.; Küper, S. Mater. Res. Soc. Symp. Proc. 1988. $101,139$.

(6) Domen, K.; Chuang, T. J. Phys. Rev. Lett. 1987, 59, 1484.

(7) Stuke, M. Appl. Phys. Lett. 1984, 45, 1175.

(8) Larciprete, R.; Stuke, M. Appl. Phys. 1987, B42, 181. the axis of the ion optics electrodes and the dye laser beam focuses at this axis. In other words, for the adsorbed-phase study the dye laser beam focus is about $10 \mathrm{~mm}$ above the substrate which is irradiated by the excimer laser as shown in Figure 1a. This noncollinear arrangement of the UV excimer photolysis laser and the tunable dye detection laser beams is quite different from the gas-phase study where the two laser beams collinearly counterpropagrate through the ionization region (see Figure 1 of ref 9 ). Therefore, by changing the time delay between the photolysis excimer laser and the detection dye laser, the velocity of the species removing from the surface can be measured accurately, because the dye laser focus is on the order of $100-\mu \mathrm{m}$ diameter and the distance of this focus from the surface about $10 \mathrm{~mm}=10000$ $\mu \mathrm{m}$, resulting in an accuracy of about $1 \%$ for the determination of the species velocity. This accuracy is sufficient to detect velocity differences between different species from the same surface or to see differences between species produced in the gas phase and at the adsorbate/substrate interface as will be described in more detail below. The substrate sample used was either n-type Si$(100),{ }^{10}$ which absorbs the UV excimer laser radiation, or UVtransparent quartz, polished to optical quality. The samples were cleaned with methanol before insertion into the chamber andafter pumping to $10^{-7} \mathrm{mbar}$ - exposed to several UV excimer laser shots. Since the silicon surface was covered by a native oxide layer, both substrates - silicon and quartz - should be somewhat similar for the adsorbate molecules but very different for the incoming UV laser light. In this way, the effect of energy absorption into the substrate material can be checked. To make sure no signal detected is due to desorption of some contaminant from the substrate, the substrate was exposed to the excimer laser light in the base pressure of $5 \times 10^{-7}$ mbar before it is exposed to an Al-alkyl gas to form an adsorbed layer at room temperature. Gaseous samples of aluminum alkyls, namely, trimethylaluminum (TMA), triethylaluminum (TEA), and triisobutylaluminum (TIBA) were taken from Alfa Ventron, and their purity was checked by NMR and picosecond laser mass spectroscopy. 7.11 For the adsorption of the aluminum alkyl onto the substrate, the gas with a pressure of $10^{-3}$ mbar was introduced into the chamber for $1 \mathrm{~min}$. When the chamber was reevacuated to $10^{-6}-10^{-5} \mathrm{mbar}$, approximately one monolayer of the aluminum alkyl remained on the substrate surface at room temperature. ${ }^{12}$ The excimer laser used as the photolysis source was a $\mathrm{XeCl}, \mathrm{KrF}$, or $\mathrm{ArF}$ laser at 308,248 , or $193 \mathrm{~nm}$, respectively, with a pulse duration on the order of $10 \mathrm{~ns}$. The UV laser light $(0.1-5 \mathrm{~mJ})$ was softly focused through a quartz lens $(f=240 \mathrm{~mm})$ onto the substrate surface.

(9) Larciprete, R.; Stuke M. Appl. Phys. 1986, B4I, 213.

(10) Kindly given to us by $M$. Winstel, Siemens AG München.

(11) Larciprete, R.; Stuke, M. J. Cryst. Growth 1986, 77, 235

(12) Ehrlich, D. J.; Osgood, R. M., Jr. Chem. Phys. Lett. 1981, 79, 381. 


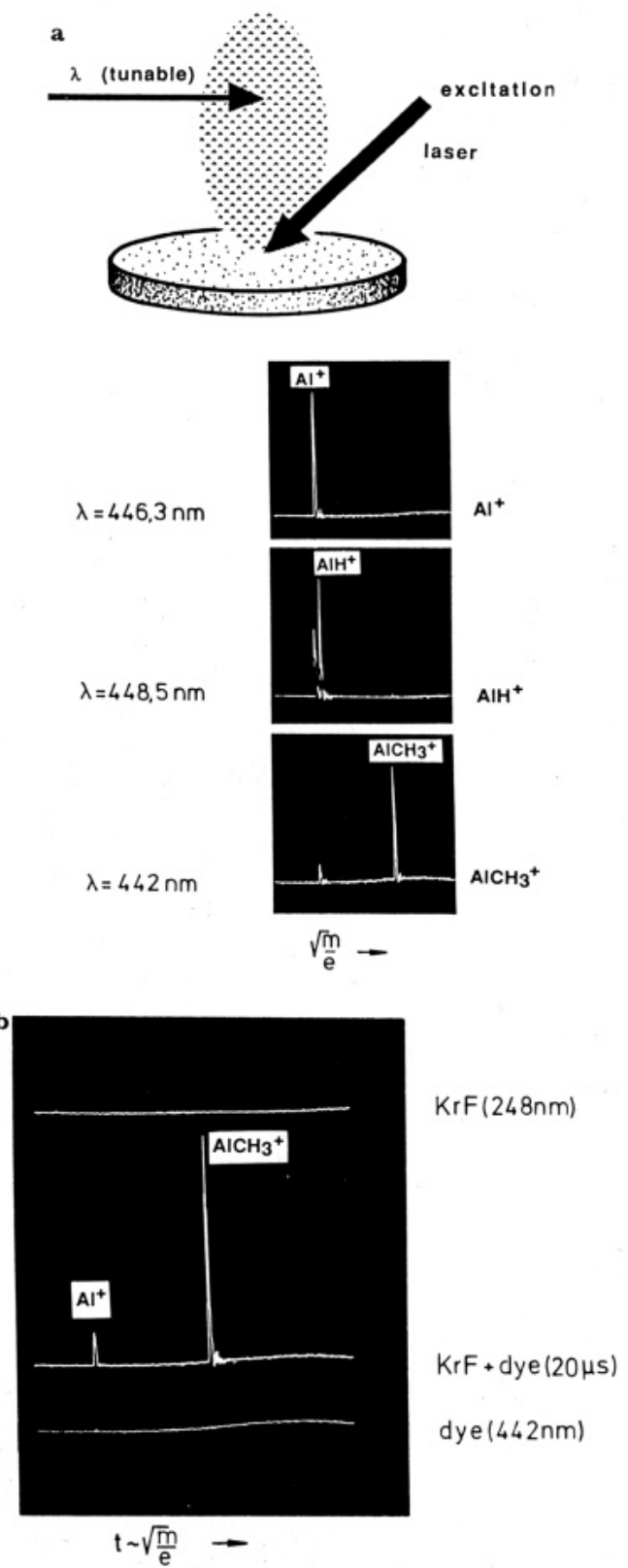

Figure 1. (a) Laser-induced photochemistry of adsorbates studied by tunable laser mass spectroscopy: different product species from adsorbed TMA detected at different dye laser wavelengths after 248 -nm excimer laser photolysis. (b) Dye laser (442-nm) single-shot detection of $\mathrm{AlCH}_{3}$ molecules formed by excimer laser photolysis of a TMA $/ \mathrm{n}-\mathrm{Si}(100)$ adsorbate interface at $248 \mathrm{~nm}$. Shown is the time-of-flight (TOF) mass spectrum with the $\mathrm{AlCH}_{3}{ }^{+}$and $\mathrm{Al}^{+}$ions, due to the corresponding neutral species (middle trace). Photolysis excimer laser (top trace) or detection dye laser (bottom trace) acting alone does not give any signal, as required.

\section{Results}

A typical result for the adsorbed TMA exposed to 248-nm laser light at a background pressure of $10^{-6}$ mbar and a time delay of $\Delta t=20 \mu \mathrm{s}$ for the dye laser set to $\lambda=442 \mathrm{~nm}$, a wavelength appropriate for the detection of $\mathrm{AlCH}_{3}$ radicals ${ }^{4}$ is given in Figure 1b. If only the excimer laser at $248 \mathrm{~nm}$ is fired, hitting the n-type $\mathrm{Si}(100)$ surface, no ions are detected after the time-of-flight drift tube (top trace). If the dye laser alone, at $\lambda=442 \mathrm{~nm}$, is fired, no signal is obtained (bottom trace). If the dye laser fires $20 \mu \mathrm{s}$ after the excimer laser, however, the TOF mass spectrum of the middle trace is obtained. The ion peaks are due to $\mathrm{Al}$ and $\mathrm{AlCH}_{3}$, as known from our previous studies on isolated TMA molecules. ${ }^{4}$ It seems important to mention here that the signal is obtained without averaging; a single shot is enough for the detection of the species removed from the surface with good signal to noise ratio.

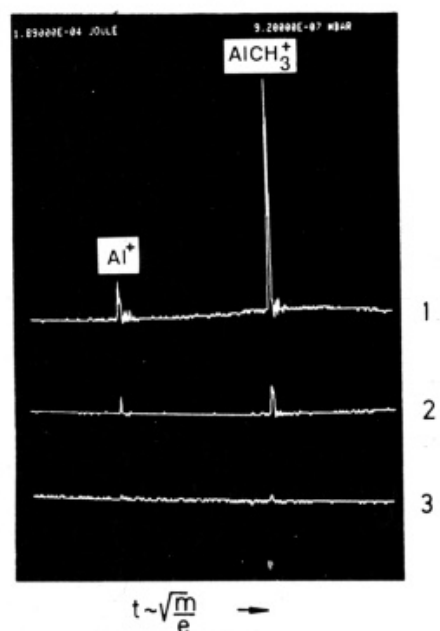

Figure 2. Dye laser (442-nm) single-shot detection of $\mathrm{AlCH}_{3}$ molecules formed by $248-\mathrm{nm}$ excimer laser photolysis of a TMA $/ \mathrm{n}-\mathrm{Si}(100)$ adsorbate interface at background pressure of $10^{-6} \mathrm{mbar}$. The TOF mass spectra with the $\mathrm{AlCH}_{3}{ }^{+}$ions are obtained for the first three laser pulse exposures, showing the depletion of the adsorbed TMA by three excimer laser pulses, where the time delay between successive shots is $1 \mathrm{~s}$.

This fact is essential for the characterization of surfaces, since each additional laser shot will see the surface which has already been exposed to one or more laser shots and therefore, in most cases, is chemically modified.

Figure 2 shows the TOF mass spectra obtained when the adsorbed TMA layer is exposed to the first three laser pulses, respectively. The $\mathrm{AlCH}_{3}{ }^{+}$signal is decreasing with increasing number $n$ of shots, due to the depletion of the adsorbed TMA from the surface. This fact indicates that, for a background pressure of about $10^{-6} \mathrm{mbar}$ and room temperature, recoverage and rediffusion have only minor effects at the laser repetition rate of $1 \mathrm{~Hz}$. This relatively low rate is chosen in order to make sure that different laser shots will see the same substrate temperature. At this repetition rate, however, when the pressure is as high as $10^{-5} \mathrm{mbar}$, the recoverage from the ambient gas can be observed since the signal induced by the next shot does not decrease under these conditions. Even though the molecular impingement frequency is about one monolayer per second at $10^{-6} \mathrm{mbar}$, the fact that it takes $10^{-5}$ mbar to observed recoverage effects is not surprising since the sticking coefficient of gas-phase species on the $\mathrm{SiO}_{2}$ surface is very small. ${ }^{12}$ The signal detected from the adsorbed-phase product tends to saturate above $2 \times 10^{-5} \mathrm{mbar}$, whereas that from the gas-phase product varies linearly with the gas pressure.

Changing the time interval between consecutive laser exposures of the surface covered by TMA (at a background pressure of $10^{-6}$ mbar), the TOF mass spectra of Figure 3 are obtained. The top trace shows the signal obtained for the first shot (compare Figure $1 \mathrm{~b}$; the other traces show the signals obtained for the second shots (down from the top) after 1,10 , and $60 \mathrm{~s}$, respectively. The increase of the $\mathrm{AlCH}_{3}{ }^{+}$signal with longer time intervals shows the effect of recoverage from the background environment and, more importantly, by rediffusion of unphotolyzed adsorbed species from the surrounding area kept at room temperature, in this case. ${ }^{12}$

If the dye laser wavelength is tuned to 446.3 and $448.5 \mathrm{~nm},{ }^{3}$ similarly, $\mathrm{Al}^{+}$and $\mathrm{AlH}^{+}$can also be detected by TOF mass spectroscopy from adsorbed Al-alkyls (TMA, TEA, and TIBA) at $248 \mathrm{~nm}$ (see Figure 1a). Since the $\mathrm{Al}^{+}$and $\mathrm{AlH}^{+}$signals were checked and found to behave similarly to the $\mathrm{AlCH}_{3}{ }^{+}$signal shown above (Figures 1b-3), only the data on $\mathrm{AlCH}_{3}{ }^{+}$will be considered in further detail here.

A preliminary comparison of n-type and p-type $\mathrm{Si}(100)$ substrates with quartz substrates has not shown any consistent difference so far.

Figure 4 (top trace) gives the dye laser wavelength dependence of the $\mathrm{AlCH}_{3}{ }^{+}$peak shown in Figure $1 \mathrm{~b}$ but at the ambient pressure of $10^{-5} \mathrm{mbar}$, compared to the spectrum from gas-phase 


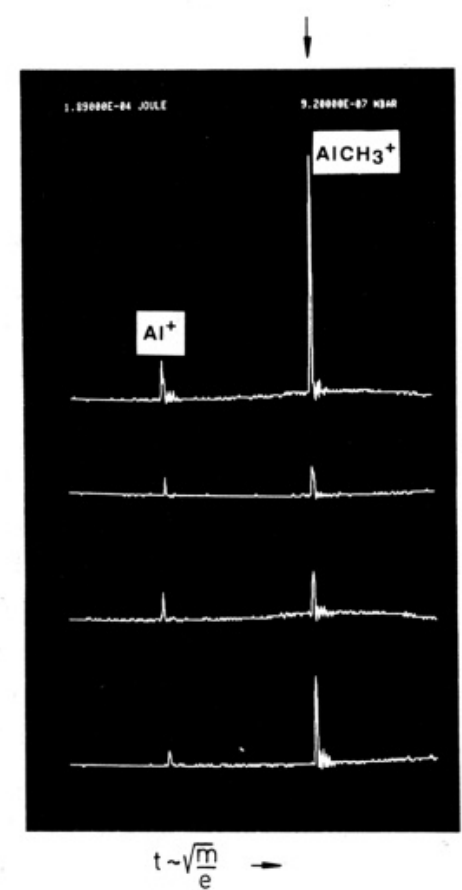

Figure 3. Time delay change between consecutive laser (248-nm) exposures of the surface covered by TMA (at a background pressure of $10^{-6}$ mbar) to obtain these TOF mass spectra $(442 \mathrm{~nm})$. The top trace shows the signal obtained for the first shot (compare Figure 1b); the other traces show the signal obtained for the second shot (down from the top) after 1,10 , and $60 \mathrm{~s}$, respectively. The increase of the $\mathrm{AlCH}_{3}{ }^{+}$signal with increased time intervals shows the effect of recoverage from the background environment and, more importantly, by rediffusion of adsorbates from the surrounding substrate material kept at room temperature. This shows that surface migration can be studied in the way.

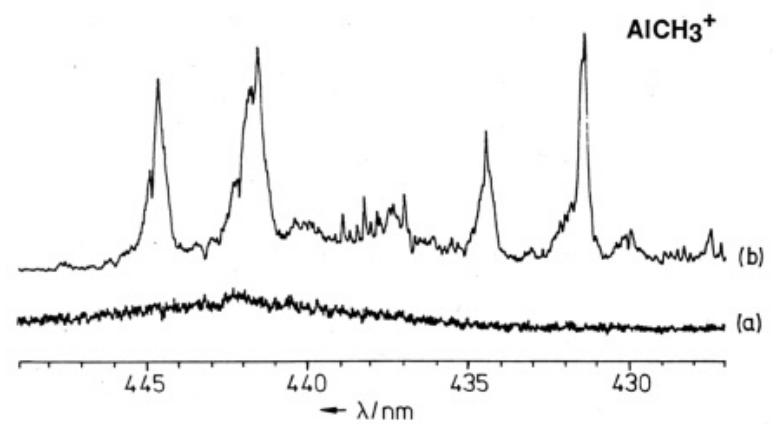

Figure 4. Dye laser wavelength dependence of the $\mathrm{AlCH}_{3}{ }^{+}$ion peak for surface adsorbate TMA molecules (top trace (b), $\mathrm{KrF}+$ dye $(20 \mu \mathrm{s})$ ) and gas-phase TMA molecules (bottom trace (a), $\mathrm{KrF}+$ dye $(0.5 \mu \mathrm{s})$ ), both at an ambient pressure of $10^{-5} \mathrm{mbar}$.

TMA (bottom trace), both for 248-nm photolysis. Similarly, when the dye laser was tuned from 441 to $450 \mathrm{~nm}$, the spectrum of the $\mathrm{Al}^{+}$signal can be obtained from 248-nm laser photolysis of the adsorbed TMA, TEA, and TIBA at the ambient pressure of $10^{-5}$ mbar, shown in Figure 5. The assignment for these spectra of $\mathrm{Al}^{+}$(Figure 5) and $\mathrm{AlCH}_{3}{ }^{+}$(Figure 4) are known from the previous studies on the $\mathrm{Al}$-alkyls under the isolated gas-phase conditions. ${ }^{3,4,13}$

Photoproducts from the adsorbed precursor or the gaseous precursor can be distinguished by the time delays $\Delta t$ for the detection dye laser as shown in Figure 6, due to the different geometrical overlap conditions of the UV excimer photolysis and the tunable dye detection lasers for these two cases. In the case of the collinear arrangement, ${ }^{9}$ the dependence of the signal on the delay time is mainly given by the removal rate of the neutral photolysis products out of the focal volume of the detection dye laser perpendicular to the laser beam axis (early linear part in Figure 6 up to about $1 \mu \mathrm{s}$, points marked by the solid triangles),

(13) Hackett, P. A.; John, P. J. Chem. Phys. 1983, 79, 3593.

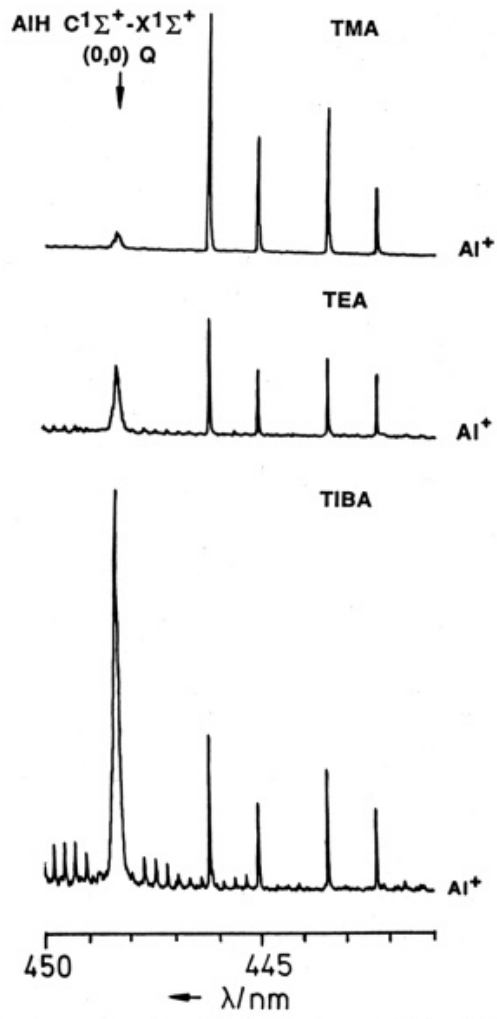

Figure 5. Dye laser wavelength dependence of the $\mathrm{Al}^{+}$ion signal for different $\mathrm{Al}$-alkyl $/ \mathrm{n}-\mathrm{Si}(100)$ adsorbate interfaces respectively, under $\mathrm{KrF}$ + dye $(10 \mu \mathrm{s})$ at a pressure of $10^{-5} \mathrm{mbar}$. The assignment for the spectrum of $\mathrm{Al}^{+}$is known from our previous studies on the isolated Al-alkyls, ${ }^{3}$ where in addition to four sharp atomic resonance peaks, ${ }^{13} \mathrm{a}$ molecular band due to the fragmentation of $\mathrm{AlH}^{+}$is present.

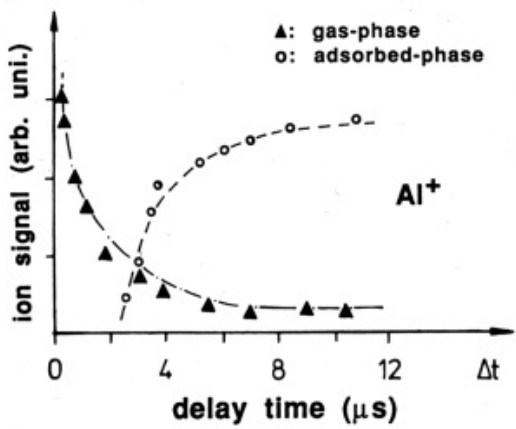

Figure 6. Dependence of the $\mathrm{Al}^{+}$ion signal on the delay time $\Delta t$ between the photolysis excimer laser $(248 \mathrm{~nm})$ and the detection dye laser $(446.3$ $\mathrm{nm}$ ) for a nominal distance between surface and dye laser focal volume of $d=10 \mathrm{~mm}$ (points marked by 0 ) and for the gas phase for a collinear laser beam geometry (points marked by $\mathbf{\Lambda}$ ).

whereas the signal for longer times is mainly governed by the species moving on axis, therefore having more time before leaving the dye laser focal volume. The velocity is best taken from the first part at short delay times. In the noncollinear arrangement of the laser beams, with the UV photolysis excimer laser hitting the surface and the dye laser focus being about $10 \mathrm{~mm}$ away from the surface, the signal dependence on the delay time is very different, as expected and shown in Figure 6 by the open circles. Here even the fastest species will need some time to reach the detection focal volume; therefore no signal is detected before a delay time of $\Delta t=2 \mu \mathrm{s}$.

The time delay cannot only show a difference between the same species produced in the gas phase and the adsorbed phase but can also show a difference between different species from the same surface. For two different neutral species, the atomic species $\mathrm{Al}$, and the molecular species $\mathrm{AlCH}_{3}$, the time-of-flight distribution was measured as given in Figure 7.

$\mathrm{Al}$ atoms (at $446.3 \mathrm{~nm}$ ) and $\mathrm{AlH}$ (at $448.5 \mathrm{~nm}$ ) and $\mathrm{AlCH}_{3}$ (at $442 \mathrm{~nm}$ ) molecules were detected as major neutral photo- 


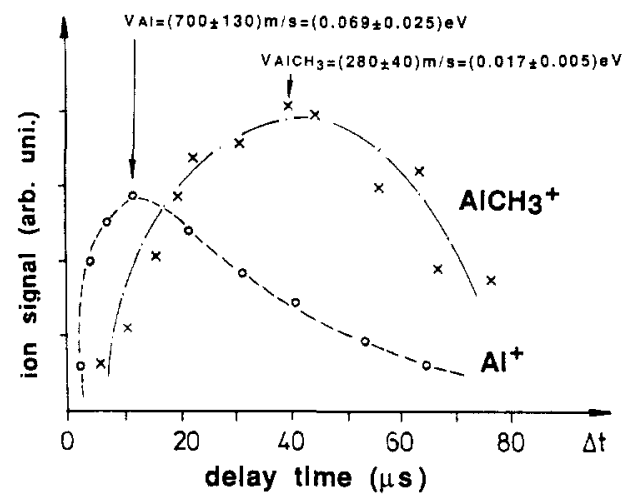

Figure 7. Dependence of the $\mathrm{Al}^{+}(446.3 \mathrm{~nm})$ and $\mathrm{AlCH}_{3}{ }^{+}(442 \mathrm{~nm})$ ion signal on the delay time $\Delta t$ between the photolysis excimer laser $(248 \mathrm{~nm})$ and the detection dye laser for a nominal distance between surface and dye laser focal volume of $d=10 \mathrm{~mm}$. The data for the $\mathrm{AlCH}_{3}{ }^{+}$ions are marked by $(X)$; the data for the $\mathrm{Al}^{+}$ions are marked by $(0)$. Al atoms and $\mathrm{AlCH}_{3}$ molecules show different peak velocities.

TABLE I: Differences between Gas-Phase and Adsorbed-Phase Photolysis at $248 \mathrm{~nm}$ for the Al-Alkyls TMA, TEA, and TIBA on n-Type Si(100), Covered by Native Oxide Layers

\begin{tabular}{lll}
\hline & \multicolumn{1}{c}{ adsorbed phe'e } & \multicolumn{1}{c}{ gas phase } \\
\hline$\Phi$ at $248 \mathrm{~nm}$, & 300 & 10 \\
$\mathrm{~mJ} / \mathrm{cm}^{2}$ & & \\
slope $n\left(S \sim \Phi^{n}\right)$ & $\gg 1$ & 1 \\
main photoproducts & Al, AlCH (from TMA) & Al (from TMA) \\
& Al, AlH (TEA, TIBA) & Al, AlH (TEA, TIBA)
\end{tabular}

products from Al-alkyls adsorbed to n-type $\mathrm{Si}(100)$ and $\mathrm{SiO}_{2}$ optical-quality quartz under UV excimer laser light, and $\mathrm{CH}_{3}$ radicals (at $333.5 \mathrm{~nm}$ ) ${ }^{4,14}$ from TMA with less signal abundance as well. For the different UV excimer laser wavelengths chosen, however, the relative abundances show marked differences between gas-phase and adsorbed-phase conditions: At $193 \mathrm{~nm}$, for TMA, TEA, and TIBA, the gas-phase neutral photoproduct signal is much higher than the signal from the adsorbate interface. At $308 \mathrm{~nm}$, only the adsorbate interface will give a signal. At 248 $\mathrm{nm}$, both gas-phase and adsorbed-phase signals are obtained, however, at different excimer laser fluences used (see Table I).

A systematic comparison between the gas phase and the adsorbed phase was made at $248 \mathrm{~nm}$. With the $248-\mathrm{nm}$ laser irradiating the $\mathrm{Al}-\mathrm{alkyl} / \mathrm{n}-\mathrm{Si}(100)$ adsorbate interface, the yield ratios of $\mathrm{AlH} / \mathrm{Al}$ can be obtained by comparing the abundances between the AlH molecular peak (at $448.5 \mathrm{~nm}$ ) and the $\mathrm{Al}$ atomic peak (at $446.3 \mathrm{~nm}$ ) for the adsorbed Al-alkyls TMA, TEA, and TIBA (see Figure 5). ${ }^{5}$ Excimer laser induced product distributions from gas-phase and adsorbed-phase molecules are shown in Figure 8 for $\lambda=248 \mathrm{~nm}$. The different fluences $(\Phi)$ between gas-phase and adsorbed-phase photolysis at $248 \mathrm{~nm}$ for the Al-alkyls are given in Table I.

\section{Discussion}

At $308 \mathrm{~nm}$, the interaction between TMA molecules and laser photons occurs at the interface $\mathrm{Al}$-alkyl/n-type $\mathrm{Si}(100)$, since gas-phase neutral products are not detected for this photolysis wavelength. This shows the influence of the environment on the process occurring and suggests that the dissociation into the smaller neutral species $\mathrm{Al}$ and $\mathrm{AlCH}$ occurs on the surface. Since this is observed, both for the $\mathrm{Si}$ and the quartz substrate, a photochemical rather than a thermal process is concluded to be the main component, since the quartz substrate should not heat up during the excimer laser photolysis. This process on the substrate can offer the so-called "photochemical prenucleation", 15 to be able to produce Al patterns by spatially selective seeding growth with a UV laser. ${ }^{1,2}$ Dependent on the UV excimer laser chosen (308,

(14) DiGiuseppe, T. G.: Hudgens, J. W.; Lin, M. C. Chem. Phys. Lett. $1981,82,267$.

(15) Ehrlich, D. J.; Osgood, R. M.; Deutsch, T. F Appl. Phys. Lett 1981, 38,946 .

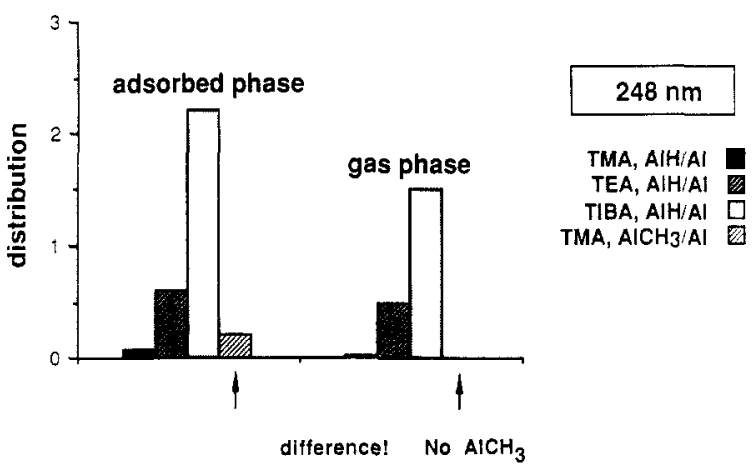

Figure 8. Comparison of distribution of relative yields of $\mathrm{AlH}$ and $\mathrm{AlCH}_{3}$ photoproducts at $248 \mathrm{~nm}$ from Al-alkyls TMA, TEA, and TIBA in the gas phase and adsorbed phase. The arrow marks the pronounced difference between the relative yields of gas-phase and adsorbed-phase $\mathrm{AlCH}_{3}$ photoproduct molecules.

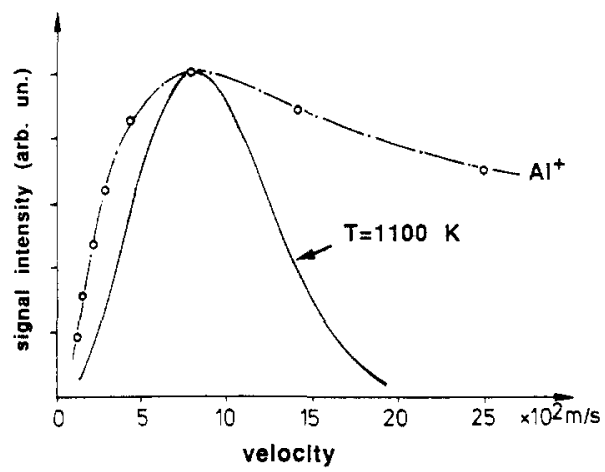

Figure 9. Velocity distribution of $\mathrm{Al}^{+}$signal, resulting from its time distribution given in Figure 7, compared to the Maxwell-Boltzmann distribution at $T=1100 \mathrm{~K}$. This figure shows that there are more fast $\mathrm{Al}$ atoms produced during photodissociation of TMA adsorbates at room temperature.

248 , or $193 \mathrm{~nm}$ ), the relative abundance of the photoproducts from the adsorbed phase shows marked differences from that of the gas-phase photoproducts. This may be due to different absorption cross sections between gas phase and adsorbed phase for different UV wavelengths. ${ }^{12,16}$

It is obvious from Figure 8 that there is a strong similarity between the distributions of the yields of gas-phase and adsorbed-phase (at least for the $\mathrm{n}-\mathrm{Si}(100)$ substrate) photoproduct $\mathrm{AlH}$ molecules from the Al-alkyls TMA, TEA, and TIBA at 248 $\mathrm{nm}$. This, however, is not true for $\mathrm{AlCH}$, which shows much higher abundance from the adsorbed phase than from the gas phase for TMA at $248 \mathrm{~nm}$. The reason why the major Al-containing molecular product changes from $\mathrm{AlCH}_{3}$ to $\mathrm{AlH}$ when the adsorbate changes from TMA via TEA to TIBA can be explained by a UV (laser) light induced reaction mechanism involving $\beta$ hydrogen elimination, similar to gas-phase photolysis. ${ }^{3}$ The reason why more AlH molecules are produced in TIBA than in TEA is that the $\beta$-hydrogen elimination proceeds more easily for branched-chain alkyls than for straight-chain ones. ${ }^{17}$ In the previous studies on adsorbed TIBA, however, AIH molecules were not expected as a product even though the $\beta$-hydrogen elimination was considered. ${ }^{1,18}$ Volatile $\mathrm{C}-\mathrm{H}$ bond containing radicals $\mathrm{CH}_{3}{ }^{16,19,20}$ and $\mathrm{CH}^{21}$ were found as products from the adsorbed TMA before, but no Al-C bond containing neutral species. It

(16) Higashi, G. S.; Rothberg, L. J. Appl. Phys. Lett. 1985, 47, 1288.

(17) Zieger, K. In Organometallic Chemistry; Ed: Zeiss, Reinhold: New York, 1960.

(18) Levy, R. A.; Green, M. L.; Gallagher, P. K. J. Electrochem. Soc. $1984,131,2177$

(19) Squire, D. W.: Dulcey, C. S.; Lin M. C. J. Vac. Sci. Technol. 1985, B3, 1513 .

(20) Higashi, G. S.; Rothberg, L. J. J. Vac. Sci. Technol. 1985, B3, 1460

(21) Motooka, T.; Gorbatkin, S;; Lubben, D.; Eres, D.; Greene, J. E. J. Vac. Sci. Technol. 1986, A4, 3146. 
was suggested earlier ${ }^{21}$ that $\mathrm{Al}-\mathrm{C}$ bond formation may occur on the $250^{\circ} \mathrm{C}$ film for TMA. We detected the $\mathrm{AlCH}_{3}$ molecules at room temperature. Since the $\mathrm{AlCH}_{3}$ molecules are reactive radicals and do have carbons tightly connected to $\mathrm{Al}$ atoms, this may be one important reason for the fact that TMA is not well suited as an organometallic precursor of high-purity aluminum films.

The high laser fluence used in the adsorbed phase when compared to the gas phase, together with a slope considerably higher than 1 (up to the order of 10) when the fluence dependence of the signal $S$ (compare Table 1) is checked, indicates the possibility of a fluence threshold. The slope $n$ seems to be higher for 308 $\mathrm{nm}$ than for $248 \mathrm{~nm}$. Shortening of the excimer photolysis laser pulse $^{22}$ will allow us to test this hypothesis. ${ }^{23}$

The velocity distributions of the $\mathrm{Al}$ atoms and of the $\mathrm{AlCH}_{3}$ molecules can be deduced from the data shown in Figures 6 and 7 for $248 \mathrm{~nm}$, and similar distributions were obtained for other wavelengths. The velocity distributions of the $\mathrm{Al}^{+}$and $\mathrm{AlCH}_{3}{ }^{+}$ signal are not the fit to the Maxwell-Boltzmann distribution, shown in Figure 9 for $\mathrm{Al}^{+}$signal as an example. The value for the most probable velocity for $\mathrm{Al}$ atoms is $V_{\mathrm{Al}}=700 \pm 130 \mathrm{~m} / \mathrm{s}$. The most probable velocity of the $\mathrm{AlCH}_{3}$ molecules is found to be about $V_{\mathrm{AlCH}_{3}}=280 \pm 40 \mathrm{~m} / \mathrm{s}$, considerably lower than the value for the Al atoms. From Figure 9, it is seen that there are more fast species here compared to the Maxwell--Boltzmann distribution, probably due to the photodissociation. The corresponding kinetic energies are $E_{\mathrm{kin}, \mathrm{Al}}=0.069 \pm 0.025 \mathrm{eV}$ and $E_{\mathrm{kin}, \mathrm{AlCH}_{3}}=0.017 \pm$ $0.005 \mathrm{eV}$ compared to the kinetic energy at room temperature of $E=0.025 \mathrm{eV}$ and a laser photon energy on the order of $5 \mathrm{eV}$. The kinetic temperature of the $\mathrm{Al}$ atoms is more than twice that of the substrate at room temperature. Since, with pulse durations for the photolysis laser on the order of nanoseconds, it is hard to

(22) Szatmari, S.; Schäfer, F. P.; Müller-Horsche, E.; Mückenheim, W. Opt. Commun. 1987, 63, 305.

(23) Küper, S.; Stuke, M. Appl. Phys. 1987, B44, 199. distinguish primary photoprocesses occurring on the surface directly, and secondary photoprocesses occurring during the same laser pulse, but in a species already removing from the surface (compare Figure 1 of ref 23), no speculations on the source of the differences for the kinetic temperature of the atomic and molecular species will be given here.

One important question still to be answered, in order to get a further understanding of those processes relevant for excimer laser induced deposition of aluminum films from Al-alkyl precursors, is the following: Does whatever is removed from the surface have any correlation with what is left behind? And what-if any-is this correlation? A combination of laser diagnostic techniques may be a solution to this topic. Work along this line is in progress.

\section{Conclusion}

Neutral UV excimer laser photoproducts from adsorbate/ substrate interfaces have been detected by single-shot tunable dye laser mass spectroscopy. For the Al-alkyls TMA, TEA, and TIBA and the substrates n-type $\mathrm{Si}(100)$ and $\mathrm{SiO}_{2}$ (quartz), aluminum atoms $\mathrm{Al}$ and the molecules $\mathrm{AlH}$ and $\mathrm{AlCH}_{3}$ were detected with abundances depending on the aluminum alkyl adsorbates. Marked differences between gas phase and the adsorbed phase are observed for $308 \mathrm{~nm}$, where only the adsorbed molecules release neutral fragments. The relative abundance of the carbon-metal-containing fragment molecule $\mathrm{AlCH}_{3}$ increases considerably when TMA is adsorbed to quartz compared to the case of free TMA molecules.

Acknowledgment. We thank D. Gudlin for measuring NMR spectra of several Al-alkyls for us, R. Larciprete for an important discussion regarding the observation of $\mathrm{AlCH}_{3}$ molecules, F. P. Schäfer for support, K. Müller for technical assistance, and, for financial support, SFB 93 (Photochemie mit Lasern, C2+C15) and BMFT (No. 13N 5398/7).

Registry No. TMA, 75-24-1; TEA, 97-93-8; TIBA, 100-99-2; Si, 7440-21-3; $\mathrm{SiO}_{2}, 14808-60-7 ; \mathrm{Al}, 7429-90-5 ; \mathrm{AlH}, 13967-22-1 ; \mathrm{AlCH}_{3}$, 76392-49-9.

\title{
Determination of the Phosphorescence Quantum Yield of Singlet Molecular Oxygen $\left({ }^{1} \Delta_{\mathrm{g}}\right)$ in Five Different Solvents
}

\author{
R. Schmidt, * K. Seikel, and H.-D. Brauer \\ Institut für Physikalische und Theoretische Chemie, Universität Frankfurt, Niederurseler Hang, \\ D 6000 Frankfurt am Main, FRG (Received: July 6, 1988; In Final Form: November 2, 1988)
}

\begin{abstract}
The quantum yield of singlet oxygen $\left({ }^{1} \mathrm{O}_{2}\right){ }^{1} \Delta_{\mathrm{g}}(v=0) \rightarrow{ }^{3} \Sigma_{\mathrm{g}}{ }^{-}(v=0)$ phosphorescence was determined in acetonitrile, chloroform, carbon disulfide, carbon tetrachloride, and Freon 113 relative to the respective emission in benzene, using the known ${ }^{1} \mathrm{O}_{2}$ phosphorescence quantum yield in benzene as standard. Quantum yields were not found to depend on sensitizer (dicyanoanthracene, rubicene, tetraphenylporphine) but to depend strongly on solvent. The ${ }^{1} \mathrm{O}_{2}$ phosphorescence quantum yields are surprisingly large. The maximum value measured is $Q_{\mathrm{P}}$ (Freon 113) $=0.15$. The emission quantum yields correlate linearly with ${ }^{1} \mathrm{O}_{2}$ lifetimes for all solvents, including benzene. Consequently the rate constant of ${ }^{1} \mathrm{O}_{2}$ phosphorescence is independent of solvent. It amounts to $k_{\mathrm{P}}=1.3 \mathrm{~s}^{-1}$. Thus the radiative rate constant is approximately 5000 times larger in liquid solution than for an isolated ${ }^{1} \mathrm{O}_{2}$ molecule.
\end{abstract}

\begin{abstract}
Introduction
The lifetime $\left(\tau_{\Delta}\right)$ of ${ }^{1} \Delta_{\mathrm{g}}$ singlet oxygen $\left({ }^{1} \mathrm{O}_{2}\right)$ is limited essentially by collisional radiationless deactivation by solvent molecules in most liquids. ${ }^{1,2}$ The mechanism of the deactivation process can be described as an electronic to vibrational energy transfer from ${ }^{1} \mathrm{O}_{2}$ to a single oscillator of the energy-accepting solvent molecule. The deactivation rate depends over a range of 4 orders
\end{abstract}

(1) Hurst, J. R.; Schuster, G. B. J. Am. Chem. Soc. 1983, 105, 5756

(2) Schmidt, R.; Brauer, H.-D. J. Am. Chem. Soc. 1987, 109, 6976. of magnitude on the nature of solvent. ${ }^{2}$

In contrast, the rate of radiative deactivation of ${ }^{1} \mathrm{O}_{2}$ appears to be much less influenced by the solvent. By calculating the oscillator strength of the $\mathrm{O}_{2}{ }^{3} \Sigma_{\mathrm{g}}-(v=0) \rightarrow{ }^{1} \Delta_{\mathrm{g}}(v=0)$ transition from absorption spectra, Long and Kearns found the radiative lifetime $\left(\tau_{p}\right)$ of ${ }^{1} \mathrm{O}_{2}$ for a series of perhalogenated solvents to be solvent independent. ${ }^{3}$ In accordance with this result Krasnovsky determined by direct observation of the ${ }^{1} \mathrm{O}_{2}$ emission via a phos-

(3) Long, C.; Kearns, D. R, J. Chem. Phys. 1973, 59, 5729 